\title{
Studies on Synthesis and Electrical Properties of CdS-Polyaniline Nanocomposite via Oxidation Polymerization
}

\author{
Kose $T D^{1, *}$, Ramteke $S P^{2}$ \\ ${ }^{1}$ Department of Chemistry A C S College Tukum Chandrapur, (MS) 4424041, India \\ ${ }^{2}$ Department of Phy sics, S P College, Chandrapur, (MS) 442401, India
}

\begin{abstract}
Nanocomposites of conducting polyaniline with CdS nanoparticles have been synthesized via in situ by oxidizing the complex of aniline with cad miu m sulfate at $3.5 \mathrm{pH}$. The effect of CdS-nanoparticles on the electrical conductivity of polyaniline was discussed. The as prepared products were characterized by FT-IR and Transmission electron Microscopy. FTIR absorption band at $3600-3500 \mathrm{~cm}^{-1}$ confirmed the highly attached polyaniline with CdS nanoparticles. TEM showed the CdS particles are spherical with the average diameter of $19 \mathrm{~nm}$ which was evenly distributed in poly mer matrix. The uniform intercalation of CdS nanoparticles results in a cooperative phenomenon between the polyaniline and the nanoparticles, as a consequence, the CdS nanoparticles increased the electrical conductivity of polyaniline nanocomposite to $6.50 \times 10^{-2}$ $\mathrm{S} / \mathrm{cm}$ compared to the pure polyaniline $\left(10^{-10} \mathrm{~S} / \mathrm{cm}\right)$; Germanium $\left(10^{-2} \mathrm{~S} / \mathrm{cm}\right)$ and Silicon $\left(10^{-4} \mathrm{~S} / \mathrm{cm}\right)$ semiconductors. Its electrical conductivity was found to be analogous with existing semiconducting metals. The fact is supported by the ample of experimental results and characterization evidences.
\end{abstract}

Keywords Nanocomposites, Nanoparticles, Cadmium Sulfide, Po lyaniline, Electrical Properties

\section{Introduction}

The nanocomposites of metal and semiconductor particles are important in several optical and electronic applications[1] and their preparation with significant effort on the ability to control the size and morphology via innovative synthetic approach is highly challeng ing particularly by using organometallic precursors. Intrinsically, conducting polymers like polyaniline have potential for wide variety of application in electronics, sensors, LED, etc owing to its easy polymerization and environmental stability [2-5]. Properties of polyaniline can be tailored by changing its oxidation states [6], acid dopants [7, 8] or through blending it with other organic or inorganic nano sized semiconducting particles [9]. It has been described that the large internal interface area in nanocomposites enables an efficient separation of charge, which is important for photovoltaic applications[10]. Polyaniline-CdS nanocomposite has been already used in photovoltaic application but formation of ionic by-products (in the reaction during the synthesis that influences the electrical properties of resulting material), indicated some restrictions in preparation of nanocomposites. There are

* Corresponding author:

t.kose@rediffmail.com (Kose T D)

Published online at http://journal.sapub.org/cmaterials

Copyright (C) 2012 Scientific \& Academic Publishing. All Rights Reserved several reports describing nanocomposites of polyaniline with semiconducting particles such as $\mathrm{TiO}_{2}, \mathrm{PbS}$ and $\mathrm{CdS}$ [11]. Polyaniline can exist in various oxidation states[12] exhibiting different properties. Transport properties of polyaniline transition metal salt composite have been studied[13]. Emeraldine base (EB) of polyaniline has been commonly used, as it is the most stable form of polyaniline. En zy matic and gas-phase plasma have been utilized in the synthesis of polyaniline[14-17]. Unfortunately, options for the processing of polyaniline are limited, since this poly mer decomposes prior to melting and it is only soluble in a few organic solvents, e.g. strong acids. This situation severely restricts the synthetic routes and desires challenging methodology for the preparation of polyaniline nanocomposites. To overcome this restriction, attempts are desired to synthesize the CdS-polyaniline nanocomposite through oxidative polymerization using hydrogen sulfide gas in solution. This study revealed a successful synthesis of incorporation of CdS-nanoparticls into polyaniline by simplest route and reported conductivities and dielectric property of CdS-polyaniline nanocomposite.

\section{Experimental}

\subsection{Reagents and Materials}

All chemicals used were of AR grade, Aniline was dis- 
tilled twice prior to use. Cadmium sulfate $\left(\mathrm{CdSO}_{4} .8 \mathrm{H}_{2} \mathrm{O}\right)$, ammon iu mpero xidisulfate $\left[(\mathrm{NH} 4)_{2} \mathrm{~S}_{2} \mathrm{O}_{8} \cdot 2 \mathrm{H}_{2} \mathrm{O}\right.$ ], hydrochloric acid, ethanol were analytical reagents and were used as received.

\subsection{Synthesis of CdS-Polyaniline Nano Composite}

Polyaniline emeraldine base (EB) and its hydrochloric salt (Polyaniline- $\mathrm{HCl}$ ) were prepared accord ing to the procedure reported in literature[18]. CdS-polyaniline nanocomposite was synthesized as follows:

Quantitative amount of $0.1 \mathrm{M} \mathrm{CdSO}_{4} .8 \mathrm{H}_{2} \mathrm{O}$ was added into the $100 \mathrm{ml} 0.5 \mathrm{M}$ aniline solution. The solution was stirred continuously for two hours to get complete dissolution under inert atmosphere of nitrogen gas. $0.5 \mathrm{M}$ $\left(\mathrm{NH}_{4}\right)_{2} \mathrm{~S}_{2} \mathrm{O}_{8} .2 \mathrm{H}_{2} \mathrm{O}$ solution was added drop wise with bubbling of $\mathrm{H}_{2} \mathrm{~S}$ gas at $3.5 \mathrm{pH}$. The reaction was carried out with constant stirring for $24 \mathrm{~h}$ at roo $\mathrm{m}$ temperature. The products were washed thoroughly plenty of times with $95 \%$ ethanol and acetone. The resulting product was dried in oven at $60^{\circ} \mathrm{C}$ for $24 \mathrm{hrs}$. The product was named as Cd S-polyaniline nano composite.

\subsection{Char acterization of Samples}

The nanoparticles formed were characterized by JEOL 2010F transmission electron microscopy (TEM).The FT-IR spectroscopy (Perkin-Elmer 100 FT-IR spectrophotometer) was used to record spectra using $\mathrm{KBr}$ pellets. The electrical conductivity of the samples was measured at temperature range from $30{ }^{\circ} \mathrm{C}-100{ }^{\circ} \mathrm{C}$ with dry pressed pallets using DFP-02 four probe set up. The capacitance and D-factor of thin pallet of a polymer sample were measured as a function of temperature using Direct Reading, LCR bridge, 8 C (Pacific), at frequency $1 \mathrm{KHz}$.

\section{Result and Discussion}

\subsection{FT-IR of CdS-Pol yaniline Nano Composite}

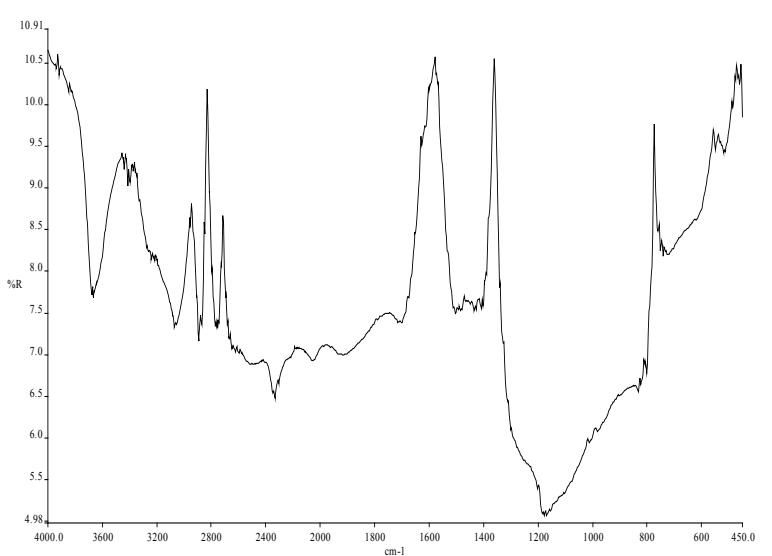

Figure 1. FT IR Spectra of CdS-polyaniline nanocomposite

Fig. 1 shows the FT-IR spectra of CdS-polyanile nanocomposite was prepared under the optimal synthetic conditions. The presence of sharp peaks near 1510 and $1605 \mathrm{~cm}^{-1}$ are attributed to $\mathrm{C}=\mathrm{C}$ stretching of the benzenoid and quinoid rings, respectively. The peak at $1298 \mathrm{~cm}^{-1}$ corresponds to $\mathrm{C}-\mathrm{N}$ stretching of secondary amine in poly mer main chain and can be clearly seen in the sample. The existence of absorption band at $1120 \mathrm{~cm}^{-1}$ has been interpreted as originating fro $\mathrm{m} p$ lane bending vibration of $\mathrm{C}-\mathrm{H}$, which was formed in the structure of $\mathrm{B}-\mathrm{N}^{+}-\mathrm{M}, \mathrm{Q}-\mathrm{N}^{+}-\mathrm{M}$ and $\mathrm{N}=\mathrm{Q}=\mathrm{N}$ during protonation of $\mathrm{CdS}$ to polyaniline. The broad absorption band ranges from 3600 to $3500 \mathrm{~cm}^{-1}$ was attributed to the protonation of amines functional group at polymer backbone and was observed for the highly attached polyaniline with CdS. Absorption band near $2900 \mathrm{~cm}^{-1}$ is assigned to aliphatic $\mathrm{C}-\mathrm{H}$ stretching of the polymer. A weak vibration absorption peak at $405 \mathrm{~cm}^{-1}$ for $\mathrm{Cd}-\mathrm{S}$ bond was observed, shows the concentrations of CdS in the composites was low.

\subsection{TEM of CdS-pol yaniline Nano Composite}

For the TEM characterization, a drop of the sample was placed on a carbon film supported by a copper grid in order to obtain electron micrographs in a JEOL 2010F Electron Microscope.

Fig. 2 shows a micrograph of $\mathrm{CdS}$ nanoparticles. The shape of the particles is spherical and the average diameter is $19 \mathrm{~nm}$ which was evenly distributed in poly mer matrix. The high resolution mic rographs of these nanoparticles display a crystal array as shown in Fig. 3

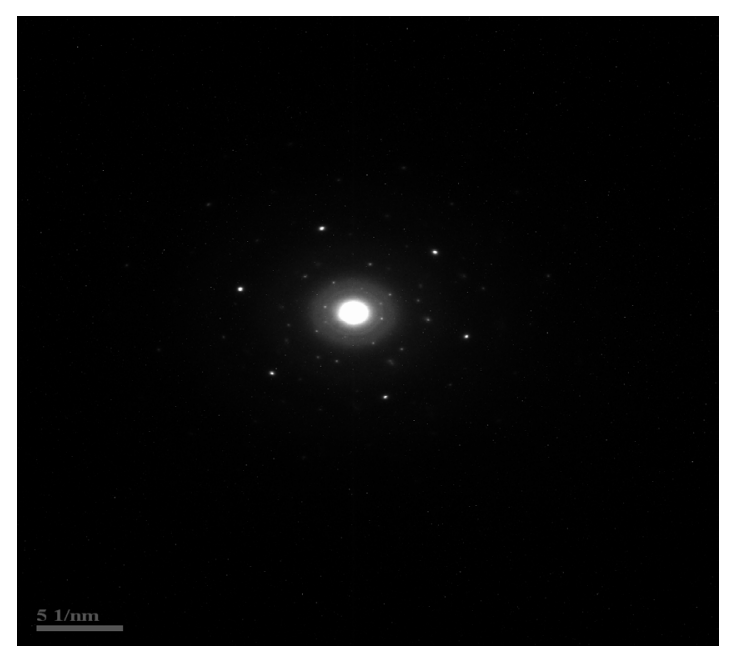

Figure 2. TEM image of CdS nanoparticles

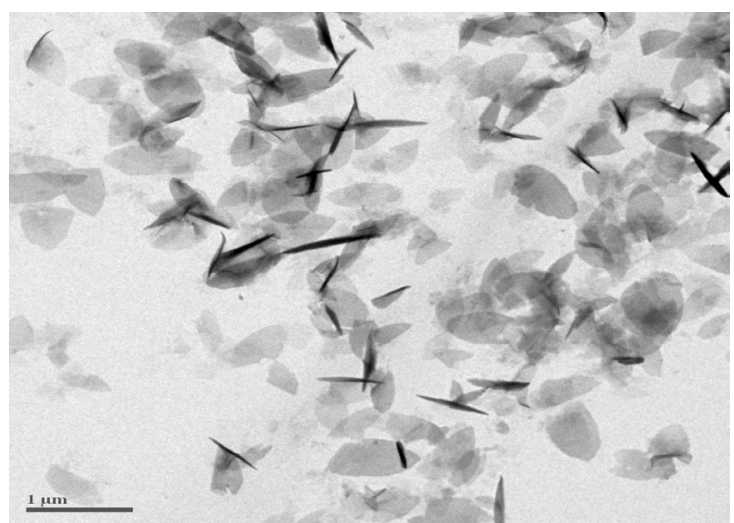

Figure 3. TEM image of CdS-Polyaniline nanocomposite 


\subsection{Electrical Conductivity}

The temperature dependence of the electrical conductivity data (in the middle range of temperature) fit the Arrhenius type of equation (1) in the temperature range investigated,

$$
\sigma(\mathrm{T})=\sigma_{0} \exp \left(-\mathrm{E}_{0} / 2 \mathrm{kT}\right)
$$

It was observed that CdS-Polyaniline nanocomposite exhibited high conductivity than pure polyaniline reported in table 1.

Table 1. Observed conductivities of CdS-polyaniline nanocomposite

\begin{tabular}{cc}
\hline Nanocomposite & Conduct ivity $\left(\mathrm{S} \mathrm{cm}^{-1}\right)$ \\
\hline CdS - Polyaniline & $6.50 \times 10^{-2}$ \\
\hline
\end{tabular}

The activation energy $\sigma_{0}(\mathrm{~T})$ was calculated from Arrhenius equation presented in table 2.

Table 2. Conductivity, Activation energy, and Dielectric constant of CdS-polyaniline nanocomposite

\begin{tabular}{|c|c|c|c|}
\hline Name of composite & $\begin{array}{c}\sigma(\mathrm{T}) \\
\mathrm{cm}^{-1} \mathrm{ohm}^{-1}\end{array}$ & $\begin{array}{c}\text { Activat ion } \\
\text { energy }(\mathrm{eV})\end{array}$ & $\begin{array}{c}\text { Dielectric } \\
\text { constant }\left(\varepsilon^{\prime}\right)\end{array}$ \\
\hline CdS-Polyaniline & $6.50 \times 10^{-2}$ & 0.30 & $1.15 \times 10^{2}$ \\
\hline
\end{tabular}

The temperature dependence of electrical conductivity of CdS-polyaniline nanocomposite shown in figure 4 .

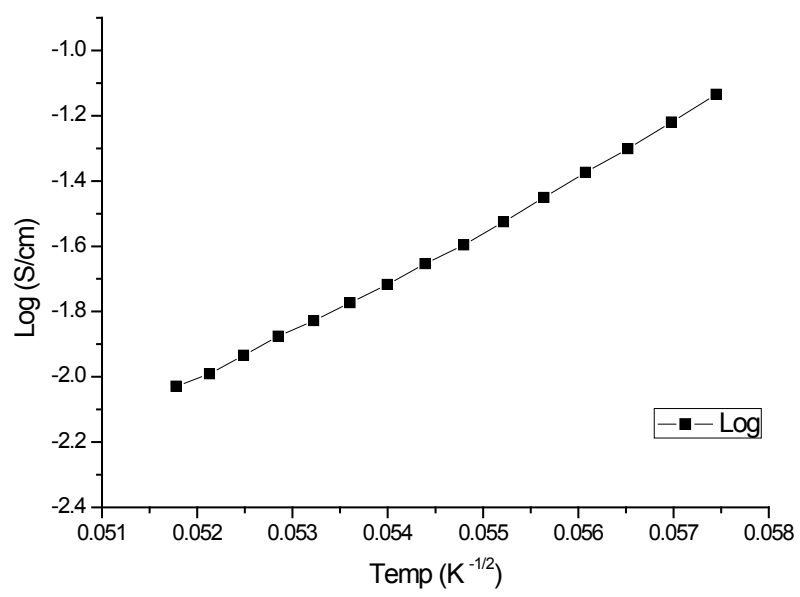

Figure 4. Temperature dependence of electrical conductivity of CdS-polyanilinenanocomposite

FTIR spectra demonstrated that CdS nanoparticles had been success fully incorporated into poly mer chain. From this result it is believed that intercalation of CdS nanoparticles in polyaniline were helped to increase the conductivity due to enhancement of crystallinity of CdS nanoparticles. The conductivity of CdS-polyaniline $\left(6.50 \times 10^{-2} \mathrm{~S} / \mathrm{cm}\right)$ nanocomposite was greater than pure polyaniline $\left(10^{-10} \mathrm{~S} / \mathrm{cm}\right)[19]$, Germaniu $\left(10^{-2} \mathrm{~S} / \mathrm{cm}\right)$ and Silicon $\left(10^{-4} \mathrm{~S} / \mathrm{cm}\right)$ semiconductors.

Thus in the present work ,cadmium sulfate and hydrogen sulfide gas was found to be more suitable for insitu preparation of Cd S-nanoparticles in polyaniline matrix. The reaction of cadmium sulfate-polyaniline solution with $\mathrm{H}_{2} \mathrm{~S}$ gas resulted in formation of nano-sized CdS (without leaving any stable by-product) at room temperature. No other gas like methane[20] was formed as a by-product in this reaction.

\section{Conclusions}

Polyaniline-CdS nanocomposites have been successfully synthesized via in situ by oxidation polymerization. FT-IR spectra demonstrated that the transition metal salt had been incorporated into polymer chain. Electrical conductivity of polyaniline-CdS nanocomposites was found to be increased when compared to pure aniline due to its increase in crystallinity. Electrical conductivity of CdS-polyaniline nanocomposite was found to be analogous with existing semiconducting metals. Cad mium sulfate in aqueous medium has been used for the first time with polyaniline and also it is the first attempt to produce nanocomposite of polyaniline-CdS via in-situ with oxidation poly merization by simplest route.

\section{ACKNOWLEDGEMENTS}

The author acknowledges authorities of Sophisticated Analytical Instrumentation Facility (SAIF) Chandigarh (INDIA), for FTIR and Nanotechnology Centre, University of Hyderabad for TEM facility.

\section{REFERENCES}

[1] Y Wang, Herron N., "Photoconductivity of CdS nanocluster-doped polymers", Chemistry and Physics Letters, vol. 200, no. 1-2, pp. 71-75, 1992.

[2] R Rosseti , J L Ellison, J M Gibsson , L E Brus , "Size effects in the excited electronic states of small colloidal CdS crystallites" Journal of Chemistry and Phy sics, vol .80, no. 9, pp., 4464-4469, 1984.

[3] Y G M Coa, P Smith, A J Heeger, "Counter-ion induced processibility of conducting polyaniline and of conducting polyblends of polyaniline in bulk polymers", Synthetic Metals. Vol.48, no. 1, pp. 91-97, 1992

[4] W Lu, R L Elsenbaumer, B Wessling, "Corrosion protection of mild steel by coatings containing polyaniline", Synthetic Metals Vol. 71, no. 1-3, pp. 2163-2166, 1995

[5] E T Kang, K G Neoh , K L Tan , "Polyaniline: A polymer with many interesting intrinsic redox states", Polymer Science, Vol. 23, no. 3, pp.277-324, 1998.

[6] H Toshikaru, H Masayashi, S Yamaguchi, "A novel redox system consisting of $\pi$-conjugated polymers and transition metals" Macromolecular Symposia, Vol.131, no. 1, pp. 59-68, 1998

[7] A Ray , G E Asturias, D L Keshner, A F Rchter, A G MacDiarmid , "Polyaniline: Doping, structure and derivatives," Synthetic Metals, vol. 29, no. 1, pp. 141-150, 1989.

[8] Liu Hongtao, Chao Danming, Liu Xincai, Jia Xiaoteng, He Libing, Cui Lili, Lei Yao, Ce Wang "Design, synthesis and characterization of a novel self-doped polyaniline derivative" 
Polymer International, vol. 60, no. 5, pp. 725-729, 2011

[9] W Feng, E Sun , A Fuji , H Hu, K Niihara, K Yoshino . "Synthesis and Characterization of Photoconducting Polyaniline- $\mathrm{TiO}_{2}$ Nanocomposite", Bulletin of the Chemical Society of Japan, vol.73, no. 11, pp. 2637-2633, 2000.

[10] Goponik N.P., Sviridov D.V. "Synthesis and Characterization of PbS Quantum Dots Embedded in the Polyaniline Film", Berichte der Bunsengesellschaft für physikalische Chemie, vol. 101, no. 11,pp. 1657-1659, 1997.

[11] D Y Godovsky, A E Varfolomeev, D F Zaretsky, R L N Chandrakanthi, A Kundig, C Weder, W Caseri, "Preparation of Nanocomposites of Polyaniline and Inorganic Semiconductors" Journal of Material Chemistry,vol.11, no. 10,pp. 2465-2469, 2001.

[12] A G MacDiarmid, J C Chaina, , L. Alcacer (Ed.), "Conducting Polymers", Reidel Publications, 1987, pp. 105.

[13] T D Kose, "Studies on transport properties of polyaniline transition metal salt composites", Journal of composite material vol.45, no. 7, pp. 831-837, 2011.

[14] S Bhadra, D Khastgir, N K Singha and J H Lee, "Progress in preparation, processing and applications of polyaniline"
Progress in Polymer Science, vol. 34, no. 8, pp. 783-810, 2009

[15] E. M. Genies, A. Boyle, M. Lapkowski and C. Tsintavis,"Polyaniline : A historical survey" Synthetic Metals vol.36, no.2, pp. 139-182,1990

[16] S. Kobayashi and A. Makino, "Enzymatic Polymer Synthesis: An Opportunity for Green Polymer Chemistry" Chemical Reviews,vol. 109,no.11,pp. 5288-5353, 2009

[17] D. Debarnot, T. Merian and F. Poncin-Epaillard, "Film Chemistry Control and Growth Kinetics of Pulsed Plasma-Polymerized Aniline" Plasma Chemistry and Plasma Processing vol.31,no.1, pp. 217-231, 2011

[18] A G MacDiarmid, J C Chiang, A F Richter, N I D Somasiri A J Epstein Aleacer Inc. L. (Ed.), "Conducting Polymers", Reidel, Dordrecht, pp.105-119, 1986

[19] A G Mac Diarmid, "Synthetic metals: a novel role for organic polymers", Current Applied Physics vol. 1, no.4-5,pp.,269279,2001 .

[20] P K Khanna, "Polyaniline-CdS nanocomposite from organometallic cadmium precursor," Material Chemistry and Physics, vol. 87, no. 1,pp. 49-52, 2004. 